\title{
MODELLING AND ANALYSIS OF TOOL WEAR ON A CRYOGENICALLY TREATED CNMG120408SMRH13A INSERT IN THE TURNING OF AISI4340 STEEL USING RESPONSE SURFACE METHODOLOGY
}

\begin{abstract}
Summary
The aim of this study is the modelling and analysis of tool wear on cryogenically treated CNMG120408SMRH13A inserts. Cryogenic treatment is carried out at $-196^{\circ} \mathrm{C}$ for 48 hours, followed by tempering at $200^{\circ} \mathrm{C}$ for 2 hours. The AISI4340 steel is machined with cryogenically treated inserts by the turning process. Parameters, namely cutting speed, feed rate, and depth of cut, are selected as the input parameters at three levels. The flank and the crater wear are considered as output responses. The Scanning Electron Microscope (SEM) and X-Ray Diffraction analyses (XRD) confirm the formation of $\eta$-phase carbides on the treated surfaces. It is found that the results obtained from this model are sufficiently accurate for the prediction of tool wear. A good correlation is shown between the theoretical predictions and the experimental data. Direct and interaction effects of process parameters on the responses are studied by plotting graphs. As a result, it is found that cryogenically treated inserts have superior tool wear resistance, which has been confirmed by conducting confirmation tests.
\end{abstract}

Key words: $\quad$ Cryogenic treatment, Tool wear, CNC turning, Response Surface Methodology (RSM).

\section{Introduction}

Tool wear is one of the major issues in machining and it greatly influences the tool life. A variety of methods, namely Physical Vapour Deposition (PVD), Chemical Vapour Deposition (CVD), and thermal spraying, are available to increase the tool life by improving the surface properties of the tool. The flank and the crater wear are the dominant wear mechanisms in the machining of materials [1]. Deep Cryogenic Treatment (DCT) is an innovative technique for improving the wear resistance of tools and a supplementary process to the conventional heat treatment. Liquid nitrogen is employed in this process at a temperature of $-196^{\circ} \mathrm{C}$. This process improves the metal properties such as strength, toughness, residual stress, crack resistance, and hardness [2]. The AISI4340 steel is high tensile alloy steel renowned for its wear resistance properties and also for high strength. In general, the AISI 4340 steel is used for making components subject to high stress, e.g. gears, studs, bolts, and components for general engineering applications such as propellers, gear shafts, connecting rods, and aircraft landing gear components [3]. In machining processes, the 
Modelling and Analysis of Tool Wear on a Cryogenically Treated CNMG120408SMRH13A Insert in the Turning of AISI4340 Steel Using Response Surface Methodology

tool wear is caused by abrasion and adhesion at lower cutting speeds and by diffusion, thermal softening, and notching at higher cutting speeds. The flank wear is a serious problem in the machining of materials irrespective of their properties conditions $[4,5]$. In the turning process, parameters such as cutting speed, feed rate, and depth of cut significantly influence the crater wear. The cutting speed increases the crater depth and decreases the width of the crater wear zone. The cryogenic treatment improves the wear resistance and hardness by decreasing the amount of retained austenite $[6,7]$.

Singh et.al [8] optimized the turning parameters, namely the cutting speed, feed rate, and depth of cut, by machining the EN24 steel. It was found that the cutting speed and the depth of cut were the factors influencing for the flank and the crater wear. Using the Analysis of Variance (ANOVA), J.P. Davim and L. Figueir [9] evaluated the influence of cutting parameters on the flank wear, specific cutting pressure and surface roughness in the turning of hardened tool steel with ceramic tools. It was also found that the selected higher cutting speed range was a factor that exerted the strongest influence of all factors. K.S. Prasad et.al [10] studied the wear behaviour in the turning of AISI 4340 hardened alloy steels with cubic boron nitride (CBN) and ceramic tools. It was observed that factors such as cutting speed, cutting forces, and temperature have a significant influence on the tool wear of CBN and ceramic inserts.

Numerous studies have been carried out to examine quantitatively the effect of cryogenic treatment on the tool materials in machining operations. S.S. Gill et.al [11] observed that shallow cryogenic treatment had notably reduced the flank wear on TiAlN-coated inserts. M.K. Sama et.al and K. Surekha et.al $[12,13]$ found that in milling operations, cryogenically treated inserts showed lower rates of flank wear and crater wear than PVD-coated and untreated inserts. A. Cicek et.al [14] studied the machinability of cryogenically treated AISIH13 tool steel with ceramic inserts and found that in the hard machining process, the cryogenic treatment decreases the tool wear rate with respect to that of untreated samples. N.A. Ozbek et.al [15] evaluated the effects of different holding times in the deep cryogenic treatment on tool wear in the turning of AISI 316 austenitic stainless steel. It was found that the best wear resistance was obtained on cutting inserts cryogenically treated for 24 hours. R. Kumar et.al [16] evaluated the performance of uncoated and cryogenically treated tools in a CA6104 lathe. It was shown that the cryogenically treated inserts had better surface finish and a lower flank wear rate than the untreated inserts. M. Strano et.al [17] studied the wear behaviour of PVD-coated and cryogenically treated tools in the turning of Ti-6Al-4V alloy and found that the cryogenic treatment prolongs the tool life during the high rate machining of titanium.

Very few researchers have quantitatively studied the effect of cryogenic treatment of different materials under various machining conditions. E. Ekici and A.R. Motorcu [18] evaluated the effect of drilling process parameters, i.e. cutting tool, cutting speed, and feed rate, on the surface roughness and tool life by using the Taguchi method. It was noted that the cryogenically treated drill had a positive effect on the surface roughness and tool life. A. Agarwal et.al [19] investigated the effect of cutting speed, feed rate, depth of cut, nose radius, and cutting environment in the CNC turning of AISI P-20 tool steel by using response surface methodology and the Taguchi method. It was found that the cryogenic environment is the most significant factor in minimizing the power consumption, followed by the cutting speed and the depth of cut. P. Sharma et.al [20] investigated the effects of machining parameters, including the workpiece hardness, on cutting forces, surface roughness, and cutting edge temperature in the finish turning of AISIH13 die tool steel with inserts. It was found that the workpiece material hardness, feed rate, and depth of cut also have a statistically significant influence on cutting forces.

The main objective of the study is to analyse the effects of process parameters, i.e. cutting speed, feed rate, and depth of cut, during the turning of AISI4340 steel with a 
cryogenically treated cutting tool. The analysis was done using second order Response Surface Methodology (RSM)-based mathematical models. The experiments were performed according to face-centred Central Composite Design (CCD) for three controllable factors, i.e. cutting speed, feed rate, and depth of cut, each at three levels.

In this study, effects of cutting speed, feed rate and depth of cut are given as input parameters to find the tool wear (flank wear and crater wear) using CNMG120408SMRH13A cutting tools under rough conditions.

This paper has three sections. The first one deals with the experimental details of machining, which includes the preparation of work materials, cryogenic treatment of selected inserts, machine setup, and machining of the work material. The second section comprises modelling by using the response surface methodology. It also includes the selection of parameters, design of experiments, wear testing and measurements, development of models, statistical analysis, and confirmation test. The last section includes the characterization of the treated tool surface done by using a scanning electron microscope and X-Ray diffraction.

\section{Experimental details}

2.1 Selection of work material and cutting tool

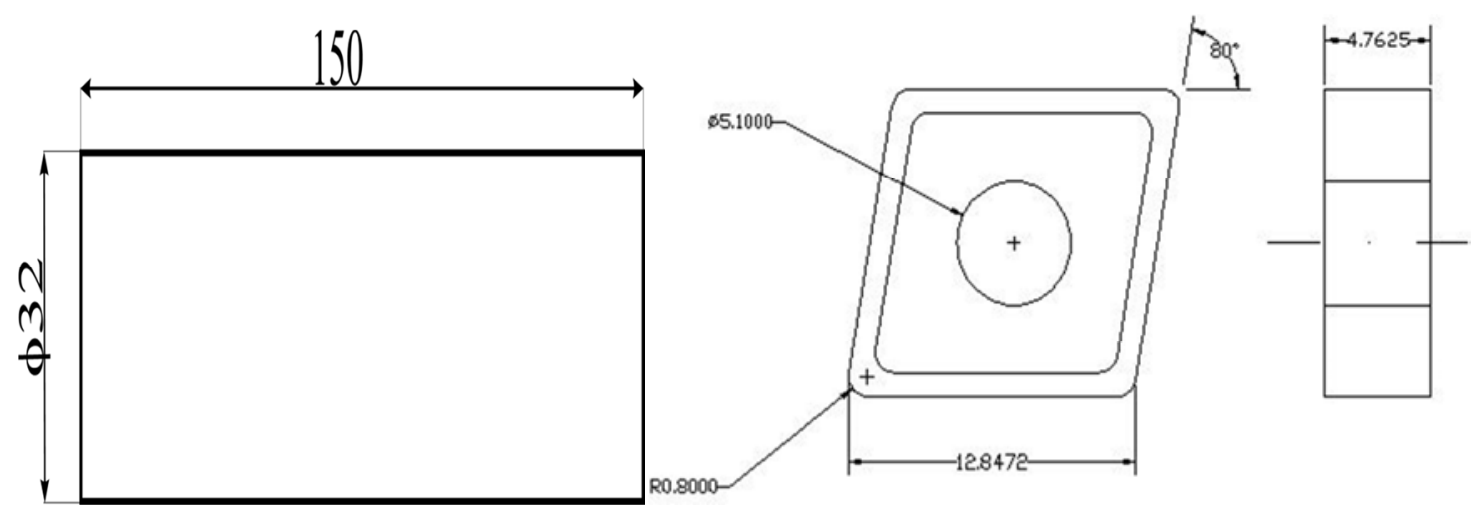

Fig. 1 A schematic diagram of the prepared work material sample and insert.

The AISI4340 steel material of $32 \mathrm{~mm}$ in diameter and $150 \mathrm{~mm}$ in length was used in all experiments. Fig. 1 shows a schematic diagram of the prepared work material sample and insert.

Table 1 Chemical composition of AISI 4340 steel

\begin{tabular}{|c|c|c|c|c|c|c|c|c|}
\hline$C(\%)$ & $S i(\%)$ & $M n(\%)$ & $S(\%)$ & $P(\%)$ & $C r(\%)$ & $M o(\%)$ & $N i(\%)$ & $F e(\%)$ \\
\hline 0.44 & 0.35 & 0.7 & 0.040 & 0.03 & 1.4 & 0.35 & 1.7 & 95 \\
\hline
\end{tabular}

The chemical composition of the work material AISI4340 is given in Table 1. The material was procured from Sun steels Ltd, Madurai, Tamilnadu, India. The workpiece materials were polished by 400 grit emery paper. The CNMG120408SMRH13A square inserts were purchased from Sandvick India Ltd, Coimbatore, Tamilnadu, India. Specifications of the CNMG120408SMRH13A insert are presented in Table 2.

Table 2 AISI4340 steel mechanical properties

\begin{tabular}{|c|c|c|c|c|c|c|c|}
\hline Description & $\begin{array}{c}\text { Size } \\
(\mathrm{mm})\end{array}$ & $\begin{array}{c}\text { Tensile } \\
\text { strength } \\
\left(\mathrm{N} / \mathrm{mm}^{2}\right)\end{array}$ & $\begin{array}{c}\text { Yield } \\
\text { stress } \\
\left(\mathrm{N} / \mathrm{mm}^{2}\right)\end{array}$ & $\begin{array}{c}\text { Elongation } \\
(\%)\end{array}$ & $\begin{array}{c}\text { Impact } \\
\text { Izod }(\mathrm{J})\end{array}$ & $\begin{array}{c}\text { Impact } \\
\text { KCV }(\mathrm{J})\end{array}$ & $\begin{array}{c}\text { Hardness } \\
(\mathrm{HB})\end{array}$ \\
\hline $\begin{array}{c}\text { Diameter/ } \\
\text { Length }\end{array}$ & $32 \times 150$ & 925 & 680 & 13 & 54 & 50 & 275 \\
\hline
\end{tabular}


2.2 Cryogenic treatment and machining details

Tool inserts made of CNMG120408SMRH13A are cooled down to a cryogenic temperature of $-196^{\circ} \mathrm{C}$ in the Dewar flask for 48 hours and then they were reheated to room temperature at a rate of $0.5^{\circ} \mathrm{C} / \mathrm{min}$. Finally, the treated inserts were tempered at $200^{\circ} \mathrm{C}$ for 2 hours. The process of cryogenic treatment is shown in Fig.2.

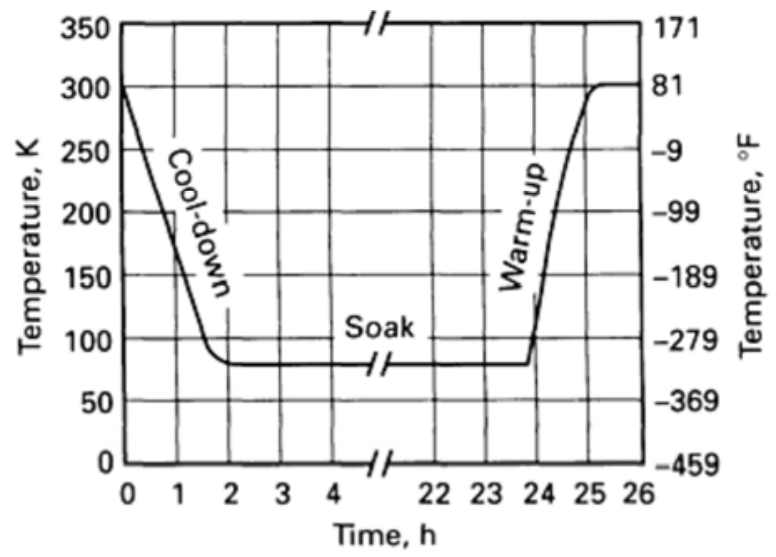

Fig. 2 Cryogenic treatment (ASM Handbook)

A galaxy Midas-6 Computer Numerical Control (CNC) universal turning machine was employed to machine the AISI4340 steel workpieces for a length of $150 \mathrm{~mm}$ under dry conditions by using cryogenically treated CNMG120408SMRH13A inserts. The cryogenically treated insert was mounted on a tool holder. The ECLNL-2525M12 tool holder was used to mount the inserts. The machining setup and the insert arrangement on the tool holder are shown in Fig.3. The AISI4340 steel workpiece was turned at a length of $40 \mathrm{~mm}$ to investigate the selected parameters at their levels. The flank and the crater wear were selected as the responses which were measured by using the tool maker microscope. A new set of inserts and workpieces were used in each experiment; each experiment was repeated three times for accuracy.
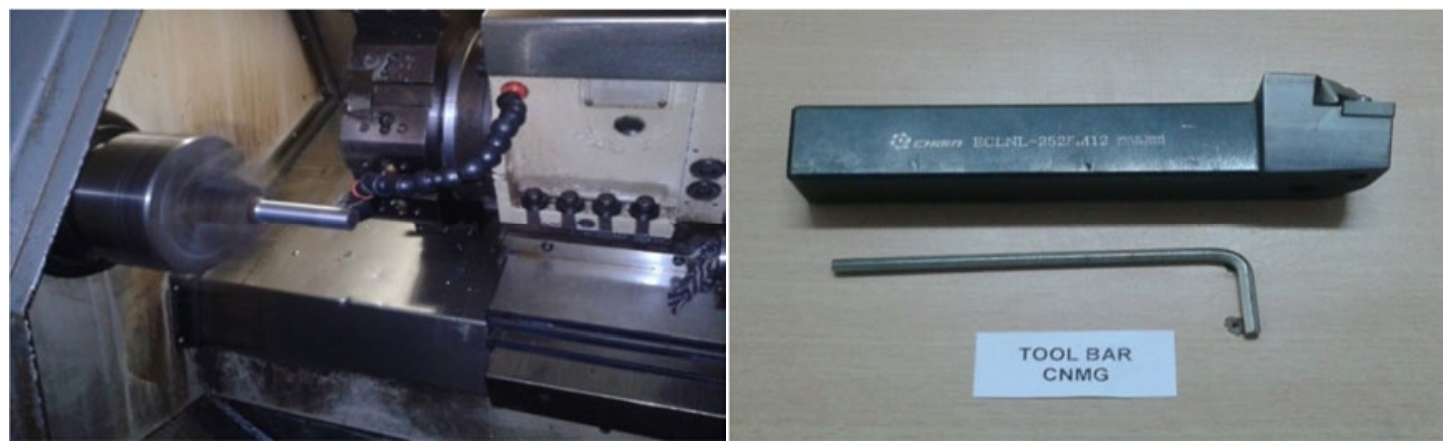

Fig. 3 CNC machine with a tool holder

\subsection{Response surface modelling}

For three independent variables $x_{1}, x_{2}$, and $x_{3}$, the response $Y$ can be represented as a function of $x_{1}, x_{2}$, and $x_{3}$ as follows:

$$
Y=f\left(x_{1}, x_{2} \text { and } x_{3}\right)+\varepsilon,
$$

where $\varepsilon$ represents the error component.

The second order RSM model can be represented by the following equation:

$$
Y=\beta_{0}+\sum_{i=1}^{k} \beta_{i} x_{i}+\sum_{i=1}^{k} \beta_{i i} x_{i}^{2}+\sum_{i, j=1}^{k} \beta_{i j} x_{i} x_{j}+\varepsilon,
$$


where $\beta_{i}(i=0,1,2 \ldots k)$ are the coefficients that have to be estimated and $\varepsilon$ represents the normally distributed random error which accounts for all the sources of variability. Denote with $\beta_{i}(i=0,1,2 \ldots k)$ the least square estimates of the unknown coefficients in Equation 3.

The expected response is expressed by:

$$
E(Y-\varepsilon)=\hat{Y}
$$

where $E$ is the error value between experimental and calculated results. Then, the surface represented by $Y=f\left(x_{1}, x_{2}\right.$ and $\left.x_{3}\right)$ is termed as the response surface.

The second order polynomial (RSM) equation is used to represent the response surface for $k$ factors and is given by:

$$
\hat{Y}=\hat{\beta}_{0}+\sum_{i=1}^{k} \hat{\beta}_{i} x_{i}+\sum_{i=1}^{k} \hat{\beta}_{i i} x_{i}^{2}+\sum_{i, j=1}^{k} \hat{\beta}_{i j} x_{i} x_{j},
$$

where $\hat{\beta}_{0}$ is the estimator of intercept, $\hat{\beta}_{1}, \hat{\beta}_{2} \ldots \hat{\beta}_{k}$ are the linear terms, $\hat{\beta}_{11}, \hat{\beta}_{22} \ldots \hat{\beta}_{k k}$ are the quadratic terms, and $\hat{\beta}_{12}, \hat{\beta}_{13} \ldots \hat{\beta}_{k-1, k}$ are the second order interaction terms.

The response function representing the tool wear can be expressed as:

$$
\hat{Y}=f(\text { cutting speed }(N) \text {, feed rate }(f) \text {, depth of cut }(D)),
$$

where $\hat{Y}$ is the response or yield.

For the three factors, the selected polynomial could be expressed as follows:

$$
\hat{Y}=\hat{\beta}_{0}+\sum_{i=1}^{3} \hat{\beta}_{i} x_{i}+\sum_{i=1}^{3} \hat{\beta}_{i i} x_{i}^{2}+\sum_{i, j=1}^{3} \hat{\beta}_{i j} x_{i} x_{j} .
$$

\subsection{Plan of investigation}

This research was planned to be carried out in the following stages:

- Identifying the important process control variables,

- Finding the upper and lower limits of process variables,

- Developing the design matrix,

- Conducting the experiment,

- Developing the mathematical models,

- Checking the adequacy of the model developed for this study,

- Analysis of the result.

\subsection{Identification of main factors}

Independently controllable process parameters affecting the tool wear are identified as speed, feed rate, and depth of cut. The identified parameters are correlated with the mathematical model [21]. The responses investigated are the flank and the crater wear. Table 3 presents the parameter levels. The coded values and the actual values of the flank and the crater wear are tabulated in Table 4. 
Table 3 Parameter levels

\begin{tabular}{|c|c|c|c|c|}
\hline \multirow{2}{*}{ No. } & \multirow{2}{*}{ Parameter / notations / units } & \multicolumn{3}{|c|}{ Parameter Levels } \\
\cline { 3 - 5 } & & 1 & 0 & 1 \\
\hline 1 & Cutting speed /N/rpm & 1000 & 1250 & 1500 \\
\hline 2 & Feed rate $/ \mathrm{f} / \mathrm{mm} / \mathrm{rev}$ & 0.1 & 0.2 & 0.3 \\
\hline 3 & Depth of cut /D/mm & 0.5 & 1 & 1.5 \\
\hline
\end{tabular}

Table 4 Coded values and actual values of tool wear

\begin{tabular}{|c|c|c|c|c|c|c|c|c|}
\hline \multirow[b]{2}{*}{ No. } & \multicolumn{3}{|c|}{ Coded value } & \multicolumn{3}{|c|}{ Actual value } & \multicolumn{2}{|c|}{ Tool wear } \\
\hline & $\begin{array}{c}\text { Cutting } \\
\text { speed }\end{array}$ & $\begin{array}{l}\text { Feed } \\
\text { rate }\end{array}$ & $\begin{array}{l}\text { Depth } \\
\text { of cut }\end{array}$ & $\begin{array}{c}\text { Cutting } \\
\text { speed (N) } \\
(\mathrm{RPM})\end{array}$ & $\begin{array}{c}\text { Feed } \\
\text { rate }(f) \\
(\mathrm{mm} / \mathrm{rev})\end{array}$ & $\begin{array}{c}\text { Depth } \\
\text { of cut }(D) \\
(\mathrm{mm})\end{array}$ & $\begin{array}{c}\text { Flank } \\
\text { wear } \\
(\mathrm{mm})\end{array}$ & $\begin{array}{l}\text { Crater } \\
\text { wear } \\
(\mathrm{mm})\end{array}$ \\
\hline 1 & -1 & 1 & 1 & 1250 & 0.1 & 1.5 & 0.5345 & 0.8467 \\
\hline 2 & 0 & 0 & 0 & 1000 & 0.2 & 1 & 0.3989 & 0.7225 \\
\hline 3 & 0 & 0 & 0 & 1250 & 0.3 & 1 & 0.4066 & 0.6655 \\
\hline 4 & 0 & 0 & -1 & 1250 & 0.3 & 0.5 & 0.2767 & 0.4228 \\
\hline 5 & 0 & 0 & 0 & 1500 & 0.1 & 1.5 & 0.6204 & 0.5646 \\
\hline 6 & 1 & 0 & 0 & 1250 & 0.1 & 1 & 0.4516 & 0.5333 \\
\hline 7 & 0 & -1 & 0 & 1000 & 0.2 & 0.5 & 0.2432 & 0.6723 \\
\hline 8 & 0 & 0 & 0 & 1500 & 0.1 & 1 & 0.4112 & 0.4786 \\
\hline 9 & -1 & 0 & 0 & 1250 & 0.3 & 1.5 & 0.5812 & 0.7467 \\
\hline 10 & 0 & 0 & 0 & 1000 & 0.3 & 1 & 0.3932 & 0.6273 \\
\hline 11 & 1 & -1 & -1 & 1000 & 0.1 & 1.5 & 0.5589 & 0.7634 \\
\hline 12 & 0 & 0 & 1 & 1500 & 0.2 & 1.5 & 0.5841 & 0.4855 \\
\hline 13 & 1 & 1 & 1 & 1500 & 0.2 & 1 & 0.4604 & 0.5057 \\
\hline 14 & 1 & 1 & -1 & 1000 & 0.2 & 1.5 & 0.5423 & 0.7254 \\
\hline 15 & 1 & -1 & 1 & 1500 & 0.3 & 1 & 0.4102 & 0.4975 \\
\hline 16 & 0 & 0 & 0 & 1500 & 0.1 & 0.5 & 0.3444 & 0.3136 \\
\hline 17 & 0 & 1 & 0 & 1250 & 0.2 & 1.5 & 0.5676 & 0.7245 \\
\hline 18 & -1 & -1 & -1 & 1500 & 0.3 & 0.5 & 0.3004 & 0.4363 \\
\hline 19 & -1 & -1 & 1 & 1250 & 0.2 & 1 & 0.4286 & 0.5989 \\
\hline 20 & -1 & 1 & -1 & 1000 & 0.3 & 0.5 & 0.2389 & 0.6435 \\
\hline 21 & 1 & 1 & 0 & 1500 & 0.3 & 1.5 & 0.5764 & 0.6978 \\
\hline 22 & 0 & -1 & -1 & 1250 & 0.2 & 0.5 & 0.2916 & 0.4734 \\
\hline 23 & -1 & 0 & 1 & 1000 & 0.1 & 1 & 0.3991 & 0.7429 \\
\hline 24 & 1 & -1 & -1 & 1500 & 0.2 & 0.5 & 0.3732 & 0.3364 \\
\hline 25 & -1 & 0 & -1 & 1000 & 0.1 & 0.5 & 0.2829 & 0.5474 \\
\hline 26 & -1 & 1 & 0 & 1000 & 0.3 & 1.5 & 0.5149 & 0.8943 \\
\hline 27 & 0 & 0 & -1 & 1250 & 0.1 & 0.5 & 0.2834 & 0.4782 \\
\hline
\end{tabular}

The minimum flank wear of $0.2389 \mathrm{~mm}$ is revealed with respect to the input parameters: speed of $1000 \mathrm{RPM}$, feed rate of $0.3 \mathrm{~mm} / \mathrm{rev}$, and depth of cut of $0.5 \mathrm{~mm}$. It can also be observed from the Table 4 that the minimum crater wear is $0.3136 \mathrm{~mm}$ and the corresponding input parameters are a cutting speed of $1500 \mathrm{RPM}$, feed rate of $0.1 \mathrm{~mm} / \mathrm{rev}$, and depth of cut of $0.5 \mathrm{~mm}$.

\subsection{Experimental design matrix}

The selected design matrix is a three factor, three level, central composite rotatable design consisting of 27 sets of coded conditions. The experiments are conducted according to the design matrix and the responses of interest are recorded. The statistical analysis software 
Treated CNMG120408SMRH13A Insert in the Turning of AISI4340 Steel Using Response Surface Methodology

is used for the analysis of the data. The coefficient values for the flank and the crater wear from the experimental test are shown in Table 5.

Table 5 Coefficient values for the flank and the crater wear from experimental test

\begin{tabular}{|c|c|c|}
\hline \multirow{2}{*}{ Coefficients } & \multicolumn{2}{|c|}{ Tool wear } \\
\cline { 2 - 3 } & Flank wear & Crater wear \\
\hline$\beta_{0}$ & 0.4246 & 0.6027 \\
\hline$\beta_{1}$ & 0.02824 & -0.1178 \\
\hline$\beta_{2}$ & -0.01044 & 0.0271 \\
\hline$\beta_{3}$ & 0.13587 & 0.1294 \\
\hline$\beta_{11}$ & 0.00052 & -0.0139 \\
\hline$\beta_{22}$ & -0.01083 & 0.0090 \\
\hline$\beta_{33}$ & 0.01086 & -0.0190 \\
\hline$\beta_{12}$ & 0.00041 & -0.0134 \\
\hline$\beta_{13}$ & -0.00735 & 0.0242 \\
\hline$\beta_{23}$ & 0.00445 & 0.0028 \\
\hline
\end{tabular}

The tests were performed at confidence level of 95\% using Student's " $t$ "-test. The estimated $t$-values for parameters and their interactions with the flank and the crater wear are given in Table 6 .

Table 6 Estimated $t$-values for parameters and their interactions with the flank and the crater wear

\begin{tabular}{|c|c|c|c|c|c|c|c|c|c|c|}
\hline Response & $t_{0}$ & $t_{1}$ & $t_{2}$ & $t_{3}$ & $t_{11}$ & $t_{22}$ & $t_{33}$ & $t_{12}$ & $t_{13}$ & $t_{23}$ \\
\hline Flank wear & 35.24 & 5.06 & -1.87 & 24.36 & 0.05 & -1.12 & 1.12 & 0.06 & -1.08 & 0.65 \\
\hline Crater wear & 23.27 & -9.83 & 2.26 & 10.76 & -0.67 & -0.43 & -0.91 & -0.91 & 1.65 & 0.19 \\
\hline
\end{tabular}

The linear, the square, and the interaction terms of the flank and the crater wear on the cryogenically treated insert are tabulated.

\subsection{Models developed for the study}

The mathematical model is based on the Response Surface Methodology (RSM) and the experiments are conducted to determine the tool wear. The responses are consequently expressed in the form of RSM equations as follows.

\subsubsection{Flank wear}

General structure of the proposed model

$$
Y=\beta_{0}+\beta_{1} N-\beta_{2} f+\beta_{3} D+\beta_{11} N^{2}-\beta_{22} f^{2}+\beta_{33} D^{2}+\beta_{12} N f-\beta_{13} N D+\beta_{23} f D
$$

Prediction of the flank wear of the proposed model

$$
\begin{aligned}
Y= & 0.4246+0.02824 N-0.01044 f+0.13587 D+0.0005 N^{2}- \\
& -0.01083 f^{2}+0,01086 D^{2}+0.00041 N f-0.00735 N D+0.00445 f D
\end{aligned}
$$

\subsubsection{Crater wear}

General structure of the proposed model

$$
Y=\beta_{0}-\beta_{1} N+\beta_{2} f+\beta_{3} D-\beta_{11} N^{2}+\beta_{22} f^{2}-\beta_{33} D^{2}-\beta_{12} N f+\beta_{13} N D+\beta_{23} f D
$$

Prediction of the crater wear of the proposed model

$$
\begin{aligned}
Y= & 0.6027-0.1176 N+0.0271 f+0.1294 D-0.0139 N^{2}+ \\
& +0.0090 f^{2}-0,0190 D^{2}-0.0134 N f+0.0242 N D+0.0028 f D
\end{aligned}
$$


2.8 Checking the adequacy of the models

The adequacies of the models are checked using the Analysis of Variance (ANOVA) technique.

Table 7 Analysis of variance of the flank and the crater wear

\begin{tabular}{|c|c|c|c|c|c|c|c|}
\hline Response & Source of variation & $D F$ & Adj $S S$ & Adj $M S$ & $F$-test & Probability $(\alpha)$ & $F_{\text {(Table Value) }}$ \\
\hline \multirow{6}{*}{ Flank wear } & Regression & 9 & 0.3509 & 0.0389 & 69.63 & 0 & \multirow{6}{*}{2.24} \\
\hline & Linear & 3 & 0.3486 & 0.1162 & 207.52 & 0.49 & \\
\hline & Square & 3 & 0.0015 & 0.0005 & 0.84 & 0.669 & \\
\hline & Interaction & 3 & 0.0009 & 0.0003 & 0.531 & - & \\
\hline & Pure Error & 17 & 0.0096 & 0.0006 & - & - & \\
\hline & Total & 26 & 0.3605 & - & - & - & \\
\hline \multirow{6}{*}{ Crater wear } & Regression & 9 & 0.57766 & 0.0641 & 24.8 & 0 & \multirow{6}{*}{2.24} \\
\hline & Linear & 3 & 0.5645 & 0.1881 & 72.72 & 0 & \\
\hline & Square & 3 & 0.0038 & 0.0012 & 0.49 & 0.639 & \\
\hline & Interaction & 3 & 0.0092 & 0.003 & 1.2 & 0.341 & \\
\hline & Pure error & 17 & 0.0439 & 0.0025 & - & - & \\
\hline & Total & 26 & 0.6215 & - & - & - & \\
\hline
\end{tabular}

The calculated value of the $F$-ratio of the model developed for this purpose does not exceed the standard tabulated value of the $F$-ratio for the desired level of confidence; hence, the models may be considered adequate within the confidence limits. Table 7 presents the analysis of variance of the flank and the crater wear.

Using a second order regression model, wear is calculated and formulated by using the Minitab 17 software, as shown in Table 8. The model includes the linear term, the square term, the interaction term, and the lack of fit term. The values of tool wear are mainly influenced by the interaction term and the calculated regression value of the $F$-ratio of the model does not exceed the tabulated value. In Table 9, the error analysis of crater wear is discussed; then, the calculated error values and the predicted values are tabulated.

Table 8 Error analyses of the flank wear

\begin{tabular}{|c|c|c|c|c|c|c|}
\hline \multirow[b]{2}{*}{ No. } & \multirow[b]{2}{*}{$\begin{array}{l}\text { Speed }(N) \\
\quad(\mathrm{rpm})\end{array}$} & \multirow[b]{2}{*}{$\begin{array}{c}\text { Feed } \\
\text { rate }(f) \\
(\mathrm{mm} / \mathrm{rev})\end{array}$} & \multirow[b]{2}{*}{$\begin{array}{c}\text { Depth of } \\
\text { cut (D) } \\
(\mathrm{mm})\end{array}$} & \multicolumn{3}{|c|}{ Flank wear } \\
\hline & & & & $\begin{array}{c}\text { Measured } \\
\text { value } \\
\text { (mm) }\end{array}$ & $\begin{array}{c}\text { Predicted } \\
\text { value } \\
(\mathrm{mm})\end{array}$ & $\begin{array}{c}\text { Error } \\
\text { value } \\
(\%)\end{array}$ \\
\hline 1 & 1250 & 0.1 & 1.5 & 0.5345 & 0.5665 & 5.9910 \\
\hline 2 & 1000 & 0.2 & 1 & 0.3989 & 0.3969 & 0.4982 \\
\hline 3 & 1250 & 0.3 & 1 & 0.4066 & 0.4033 & 0.7936 \\
\hline 4 & 1250 & 0.3 & 0.5 & 0.2767 & 0.2739 & 1.0090 \\
\hline 5 & 1500 & 0.1 & 1.5 & 0.6204 & 0.5875 & 5.3016 \\
\hline 6 & 1250 & 0.1 & 1 & 0.4516 & 0.4242 & 6.0650 \\
\hline 7 & 1000 & 0.2 & 0.5 & 0.2432 & 0.2645 & 8.7777 \\
\hline 8 & 1500 & 0.1 & 1 & 0.4112 & 0.4525 & 10.0664 \\
\hline 9 & 1250 & 0.3 & 1.5 & 0.5812 & 0.5545 & 4.5874 \\
\hline 10 & 1000 & 0.3 & 1 & 0.3932 & 0.3752 & 4.5726 \\
\hline 11 & 1000 & 0.1 & 1.5 & 0.5589 & 0.5465 & 2.2121 \\
\hline 12 & 1500 & 0.2 & 1.5 & 0.5841 & 0.5927 & 1.4836 \\
\hline 13 & 1500 & 0.2 & 1 & 0.4604 & 0.4534 & 1.5201 \\
\hline 14 & 1000 & 0.2 & 1.5 & 0.5423 & 0.5509 & 1.6001 \\
\hline 15 & 1500 & 0.3 & 1 & 0.4102 & 0.4325 & 5.4426 \\
\hline
\end{tabular}


Modelling and Analysis of Tool Wear on a Cryogenically

Treated CNMG120408SMRH13A Insert in the Turning of

AISI4340 Steel Using Response Surface Methodology

\begin{tabular}{|c|c|c|c|c|c|c|}
\hline \multirow{2}{*}{ No. } & Speed $(\mathrm{N})$ & \multirow{2}{*}{$\begin{array}{c}\text { Feed } \\
\text { rate }(f) \\
(\mathrm{mm})\end{array}$} & $\begin{array}{c}\text { Depth of } \\
\text { cut }(\mathrm{D}) \\
(\mathrm{mm})\end{array}$ & $\begin{array}{c}\text { Measured } \\
\text { value } \\
(\mathrm{mm})\end{array}$ & $\begin{array}{c}\text { Predicted } \\
\text { value } \\
(\mathrm{mm})\end{array}$ & $\begin{array}{c}\text { Error } \\
\text { value } \\
(\%)\end{array}$ \\
\hline 16 & 1500 & 0.1 & 0.5 & 0.3444 & 0.3393 & 1.4580 \\
\hline 17 & 1250 & 0.2 & 1.5 & 0.5676 & 0.5713 & 0.6556 \\
\hline 18 & 1500 & 0.3 & 0.5 & 0.3004 & 0.3104 & 3.3324 \\
\hline 19 & 1250 & 0.2 & 1 & 0.4286 & 0.4246 & 0.9315 \\
\hline 20 & 1000 & 0.3 & 0.5 & 0.2389 & 0.2384 & 0.2070 \\
\hline 21 & 1500 & 0.3 & 1.5 & 0.5764 & 0.5763 & 0.0102 \\
\hline 22 & 1250 & 0.2 & 0.5 & 0.2916 & 0.2996 & 2.7402 \\
\hline 23 & 1000 & 0.1 & 1 & 0.3991 & 0.3969 & 0.5459 \\
\hline 24 & 1500 & 0.2 & 0.5 & 0.3732 & 0.3357 & 10.0385 \\
\hline 25 & 1000 & 0.1 & 0.5 & 0.2829 & 0.2690 & 4.9112 \\
\hline 26 & 1000 & 0.3 & 1.5 & 0.5149 & 0.5337 & 3.6580 \\
\hline 27 & 1250 & 0.1 & 0.5 & 0.2834 & 0.3036 & 7.1602 \\
\hline & & Average error value & & & 3.5396 \\
\hline
\end{tabular}

Table 9 Error analyses of the crater wear

\begin{tabular}{|c|c|c|c|c|c|c|}
\hline \multirow[b]{2}{*}{ No. } & \multirow[b]{2}{*}{$\begin{array}{l}\text { Speed }(N) \\
(\mathrm{rpm})\end{array}$} & \multirow[b]{2}{*}{$\begin{array}{c}\text { Feed } \\
\text { rate (f) } \\
(\mathrm{mm} / \mathrm{rev})\end{array}$} & \multirow[b]{2}{*}{$\begin{array}{c}\text { Depth of } \\
\text { cut (D) } \\
(\mathrm{mm})\end{array}$} & \multicolumn{3}{|c|}{ Crater wear } \\
\hline & & & & $\begin{array}{c}\text { Measured } \\
\text { value } \\
(\mathrm{mm})\end{array}$ & $\begin{array}{c}\text { Predicted } \\
\text { value } \\
(\mathrm{mm})\end{array}$ & $\begin{array}{c}\text { Error } \\
\text { value } \\
(\%)\end{array}$ \\
\hline 1 & 1250 & 0.1 & 1.5 & 0.7811 & 0.6890 & 11.7834 \\
\hline 2 & 1000 & 0.2 & 1 & 0.7022 & 0.7044 & 0.3259 \\
\hline 3 & 1250 & 0.3 & 1 & 0.6655 & 0.6138 & 7.7640 \\
\hline 4 & 1250 & 0.3 & 0.5 & 0.4510 & 0.4841 & 7.3581 \\
\hline 5 & 1500 & 0.1 & 1.5 & 0.5546 & 0.5711 & 2.9917 \\
\hline 6 & 1250 & 0.1 & 1 & 0.5320 & 0.5594 & 5.1431 \\
\hline 7 & 1000 & 0.2 & 0.5 & 0.6523 & 0.5748 & 11.8742 \\
\hline 8 & 1500 & 0.1 & 1 & 0.4981 & 0.4415 & 11.3536 \\
\hline 9 & 1250 & 0.3 & 1.5 & 0.7165 & 0.7434 & 3.7648 \\
\hline 10 & 1000 & 0.3 & 1 & 0.7112 & 0.7316 & 2.8820 \\
\hline 11 & 1000 & 0.1 & 1.5 & 0.7611 & 0.8069 & 6.0210 \\
\hline 12 & 1500 & 0.2 & 1.5 & 0.5454 & 0.5984 & 9.7177 \\
\hline 13 & 1500 & 0.2 & 1 & 0.4957 & 0.4687 & 5.4356 \\
\hline 14 & 1000 & 0.2 & 1.5 & 0.7234 & 0.8341 & 15.3074 \\
\hline 15 & 1500 & 0.3 & 1 & 0.4812 & 0.4959 & 3.0680 \\
\hline 16 & 1500 & 0.1 & 0.5 & 0.3026 & 0.3119 & 3.0741 \\
\hline 17 & 1250 & 0.2 & 1.5 & 0.7244 & 0.7162 & 1.1295 \\
\hline 18 & 1500 & 0.3 & 0.5 & 0.3010 & 0.3663 & 21.7005 \\
\hline 19 & 1250 & 0.2 & 1 & 0.5989 & 0.5866 & 2.0582 \\
\hline 20 & 1000 & 0.3 & 0.5 & 0.6433 & 0.6020 & 6.4119 \\
\hline 21 & 1500 & 0.3 & 1.5 & 0.6878 & 0.6256 & 9.0420 \\
\hline 22 & 1250 & 0.2 & 0.5 & 0.4724 & 0.4569 & 3.2750 \\
\hline 23 & 1000 & 0.1 & 1 & 0.7101 & 0.6772 & 4.6217 \\
\hline 24 & 1500 & 0.2 & 0.5 & 0.3100 & 0.3391 & 9.3904 \\
\hline 25 & 1000 & 0.1 & 0.5 & 0.5001 & 0.5476 & 9.5052 \\
\hline 26 & 1000 & 0.3 & 1.5 & 0.8943 & 0.8613 & 3.6853 \\
\hline 27 & 1250 & 0.1 & 0.5 & 0.4223 & 0.4297 & 1.7687 \\
\hline & & Averas & or value & & & 6.6834 \\
\hline
\end{tabular}




\subsection{Conducting the Conformity Test}

A comparison between the model results and the experimental data can be used to assess the applicability of the proposed approach. A satisfactory correlation is found between the prediction and the experimental data. As a result, the modelling is accurate enough for predicting the tool wear of the insert. The response surface methodology has provided good prediction results. However, this approach is suitable only for few process variables [22]. The results show that the tool wear models are reliable and could be used effectively for wear prediction.

\section{Results and discussion}

3.1 Characterization of cryogenically treated CNMG 120408 SMR H13A inserts

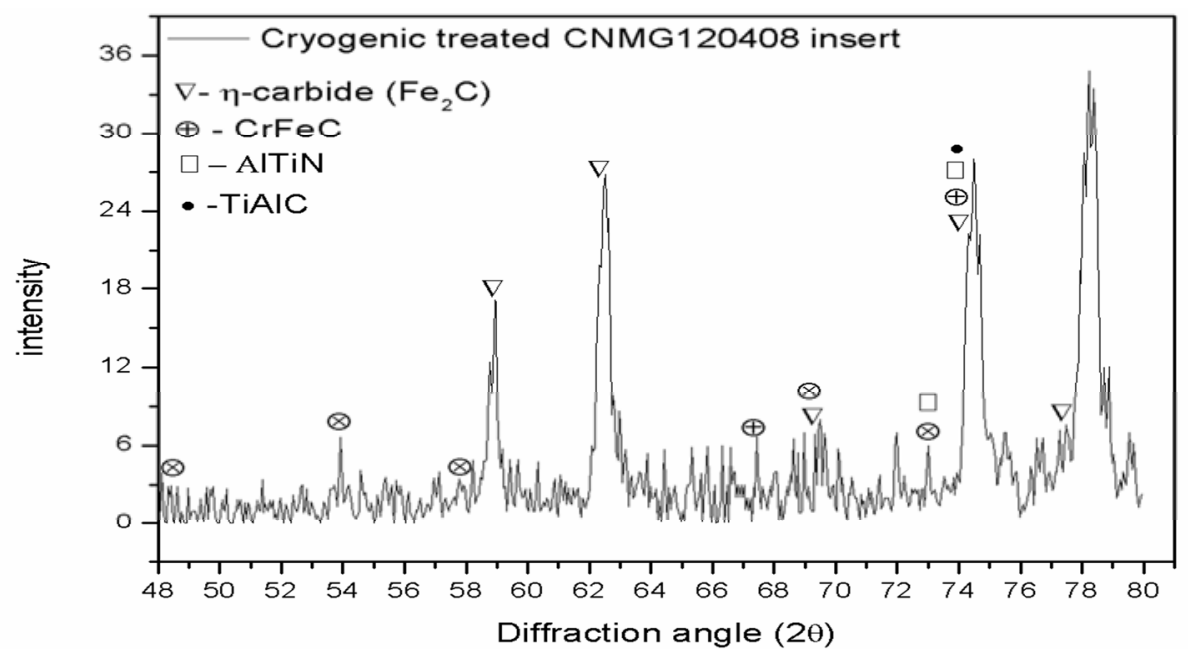

Fig. 4 XRD pattern

The XRD pattern of cryogenically treated samples is shown in Fig.4. It shows that $\eta$ carbides $\left(\mathrm{Fe}_{2} \mathrm{C}\right)$ have formed on the inserts due to cryogenic treatment. The $\eta$-carbides have an orthorhombic crystal structure which results in very high wear resistance by improving the hardness. The peak positions 54, 58, 67.5, 69.2, and 74 confirm the formation of chromium iron carbides and the peak positions 73 and 77.8 confirm the formation of aluminum titanium nitrate and titanium aluminum carbides on the cryogenically treated insert surfaces. These carbides give an excellent wear resistance to the cryogenically treated insert surface.

The SEM images confirm the formation of $\eta$-carbides on the surface of cryogenically treated inserts as shown in Fig.5. The figure shows that the cryogenically treated inserts reduce the flank and the creater wear. The cryogenic treatment sigificantly improves the hardness of the treated surface due to the formation of $\eta$-carbides, which in turn leads to an increase in the tool wear resistance. 


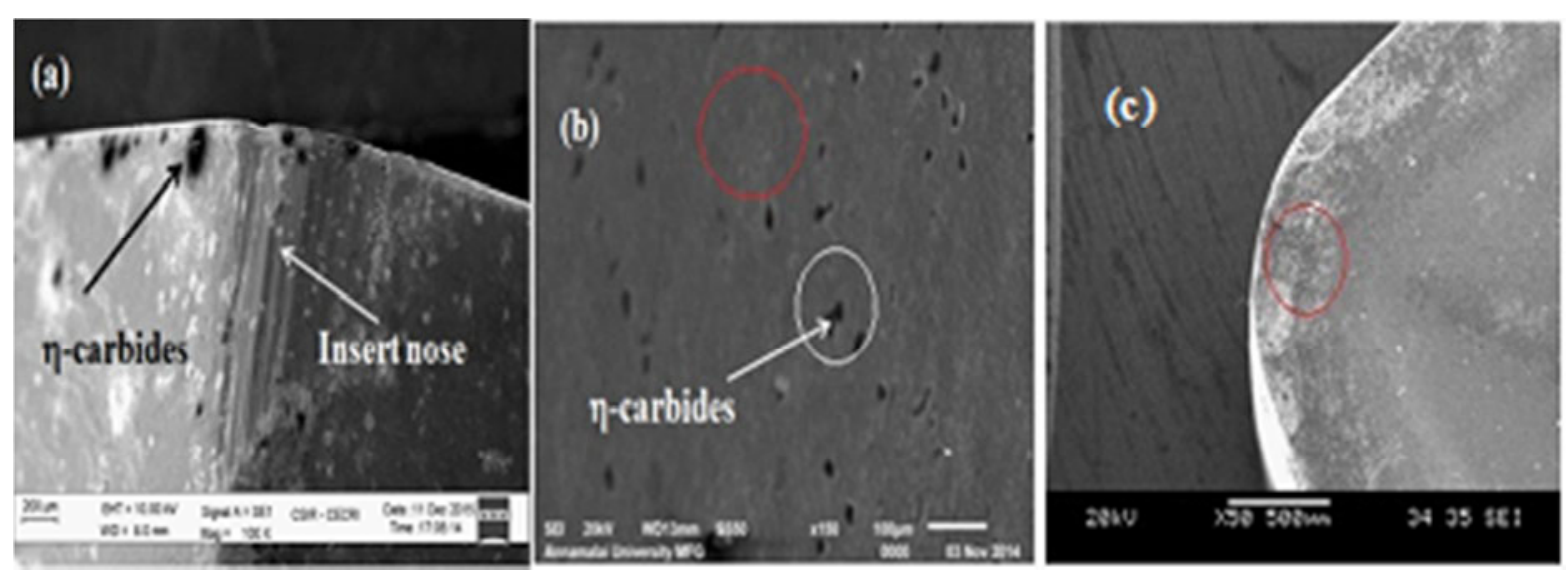

Fig. 5 SEM images of cryogenically treated insert: (a) Flank wear, (b) Carbide formation and

(c) Crater wear

\subsection{Response surface analysis}

The effects of the deep cryogenic treatment on the cutting tool wear are investigated through the RSM. The changes in the results of the flank and the crater wears are presented in Figures 6-13.

\subsection{Direct effect on the flank wear}

The variation in the flank wear with respect to the cutting parameters is shown in Fig.6. Individual effects of the selected parameters on the responses at different levels are clearly shown. It can be seen that the selected parameters have an increasing trend towards the flank wear and a decreasing trend towards the crater wear. The slope between the points clearly describes the level of influence. The magnitudes of slope in the flank wear vary from 0.2013 to 0.03155 for the depth of cut, from 0.1305 to 0.2435 for the cutting speed, and from 0.0765 to 0.1897 for the feed rate, as shown in Fig.6 (a-c).

Cutting speed (RPM)

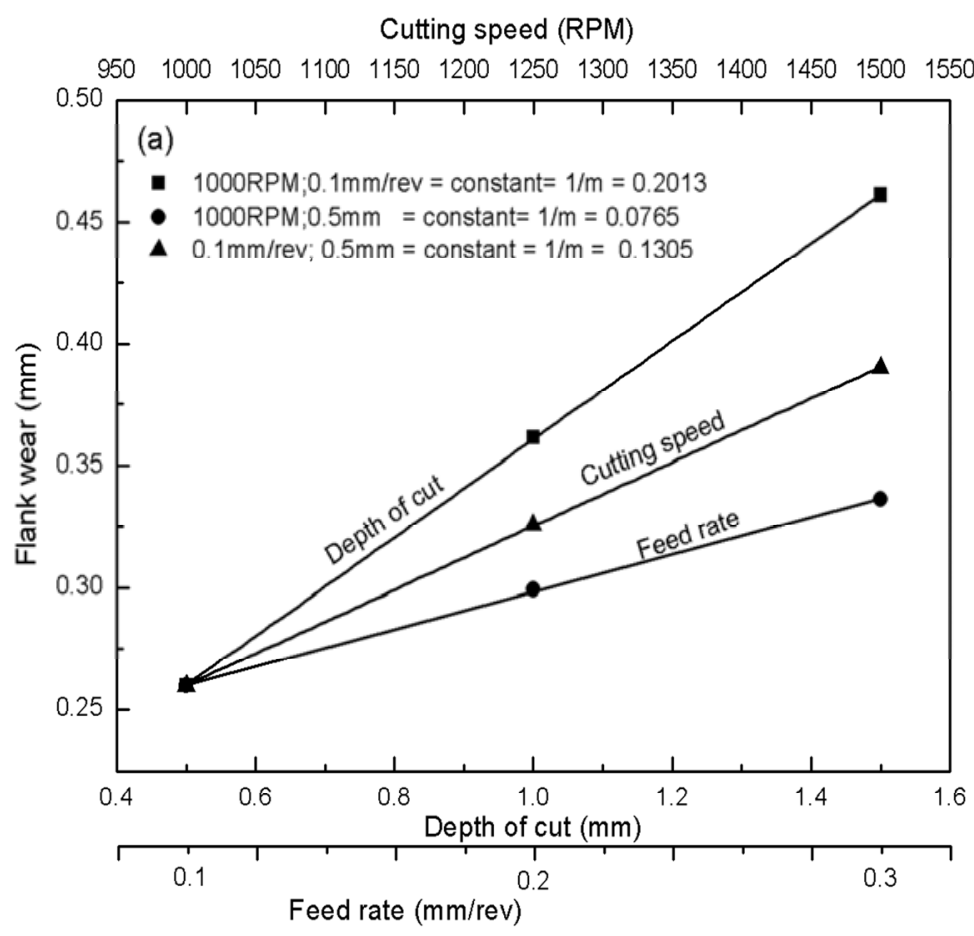


Cutting speed (RPM)

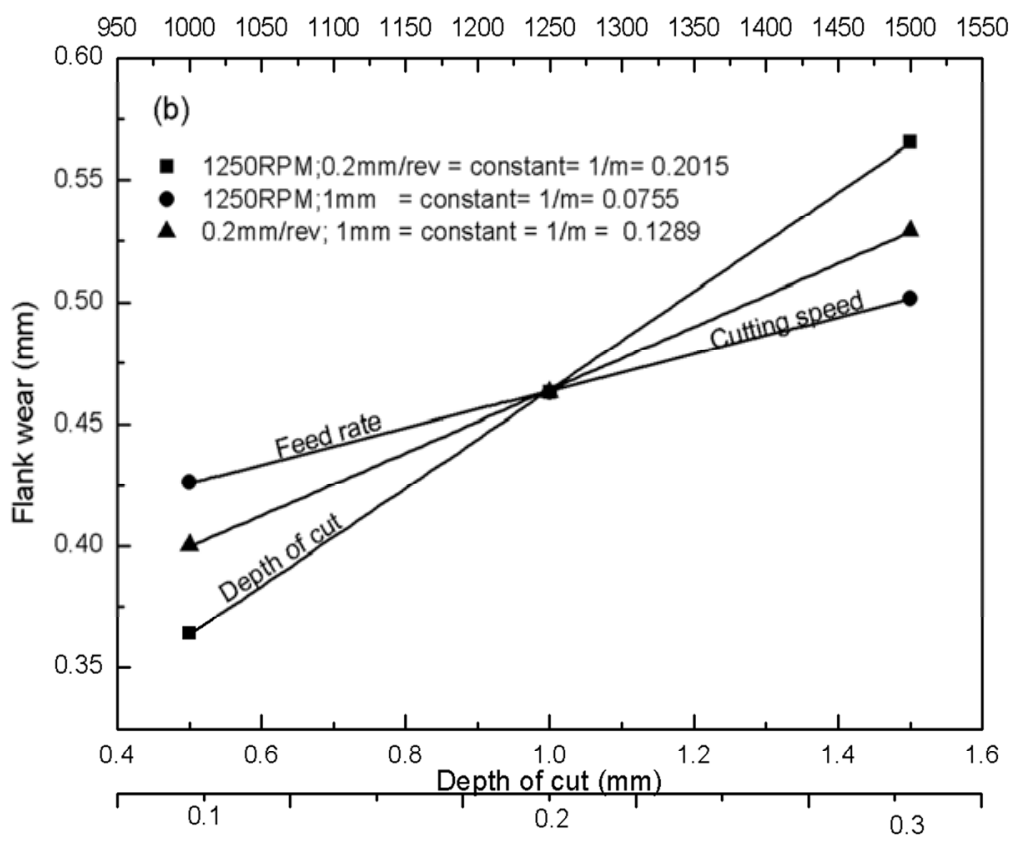

b)

Feed rate $(\mathrm{mm} / \mathrm{rev})$

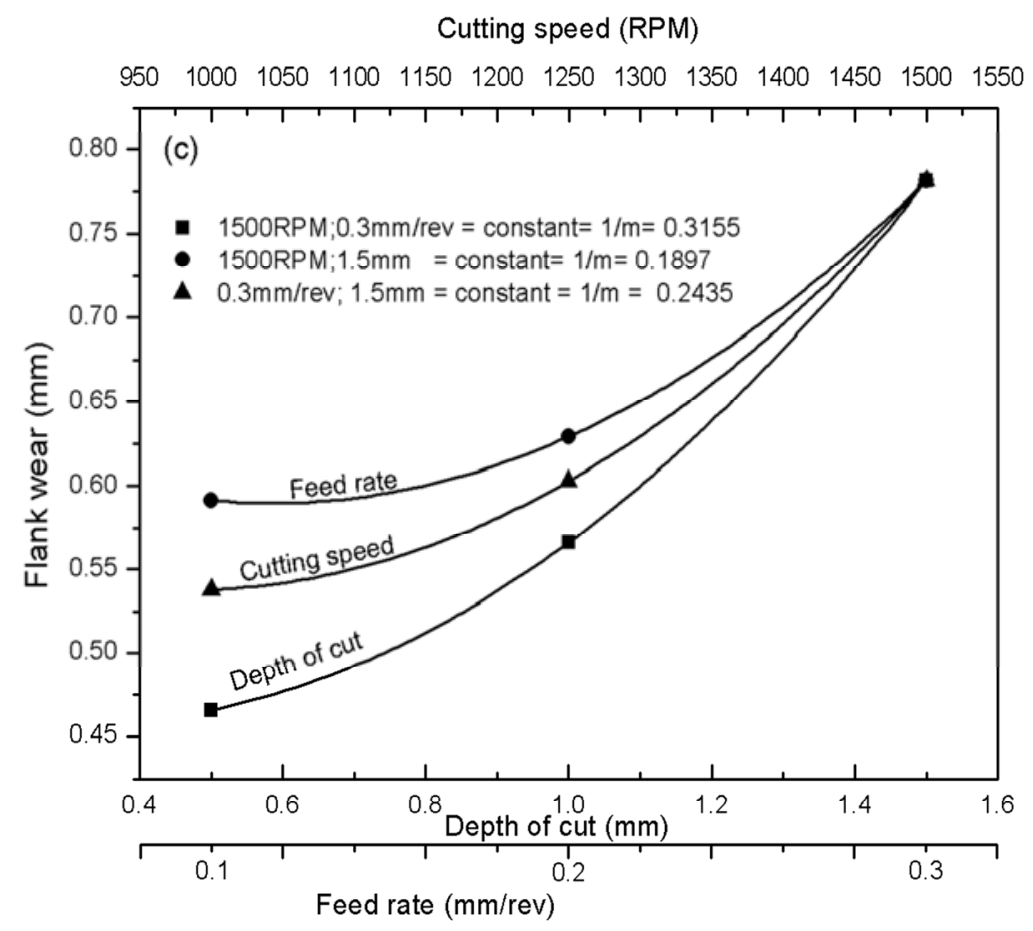

c)

Fig. 6 The direct effects on the flank wear at (a) lower, (b) middle and (c) higher levels

At the lower level, the flank wear shows an increasing trend. The flank wear increases with increased cutting speed, feed rate, and depth of cut, as shown in Fig.6 (a). At the middle level, there is an intersection trend towards flank wear, as shown in Fig.6 (b). At the higher level, as shown in Fig.6 (c), the flank wear values are higher in the feed rate, followed by the cutting speed and the depth of cut. Based on the magnitude of slope, the depth of cut has the strongest influence, followed by the cutting speed and the feed rate. The cutting forces considerably increase with the increasing depth of cut, which significantly increases the contact pressure on the face of the insert, which in turn leads to the flank wear. 


\subsubsection{Interaction effect on the flank wear}

The effect of increasing cutting speed on the tool wear is presented graphically in Fig.7. It is shown that with an increase in the cutting speed, there is an increase in flank wear; on the other hand, an increase in the feed rate results in a decrease in the flank wear. The results show that the cutting speed plays a significant role in the tool wear. Based on the results obtained in the experiment, it is determined that the cutting speed should remain low when turning the AISI4340 material in order to achieve maximum cutting performance of the insert tools.

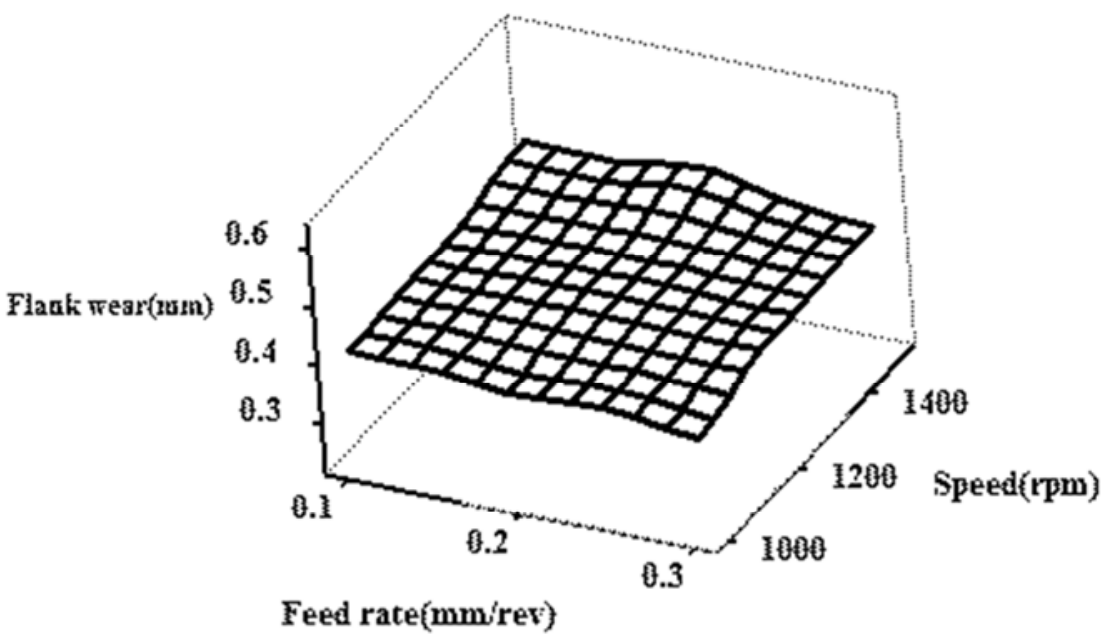

Fig. 7 Interaction between the cutting speed and the feed rate

From Fig. 8 one can see that there is an increase in wear as there is a decrease in feed rate and an increase in the depth of cut. The increase in the depth of cut causes an increase in the chip tool contact area, thereby accelerating the process of wearing. Furthermore, it is well known that the greater the depth of cut is, more heat is released, which then causes heavier wear of the tool.

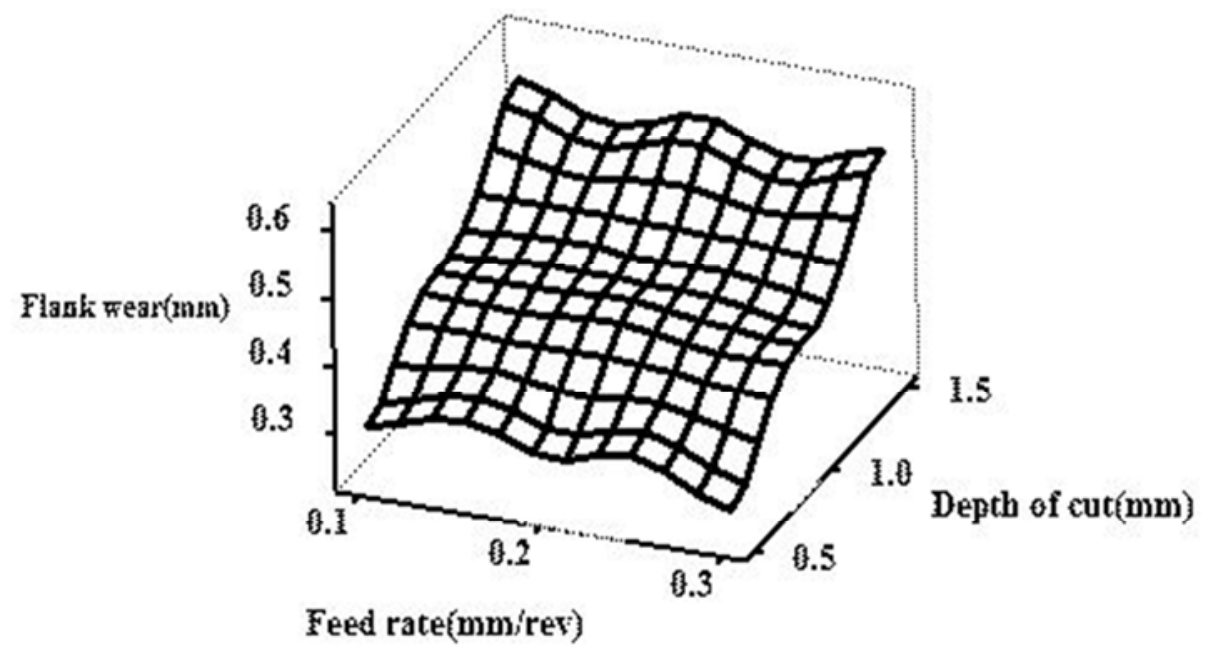

Fig. 8 Interaction between the feed rate and the depth of cut

It is clear from Fig.9 that there is an increase in wear as there is an increase in the depth of cut and the cutting speed. The larger the depth of cut is, more heat is released, and therefore, the tool wear is controlled by the cryogenic treatment. 


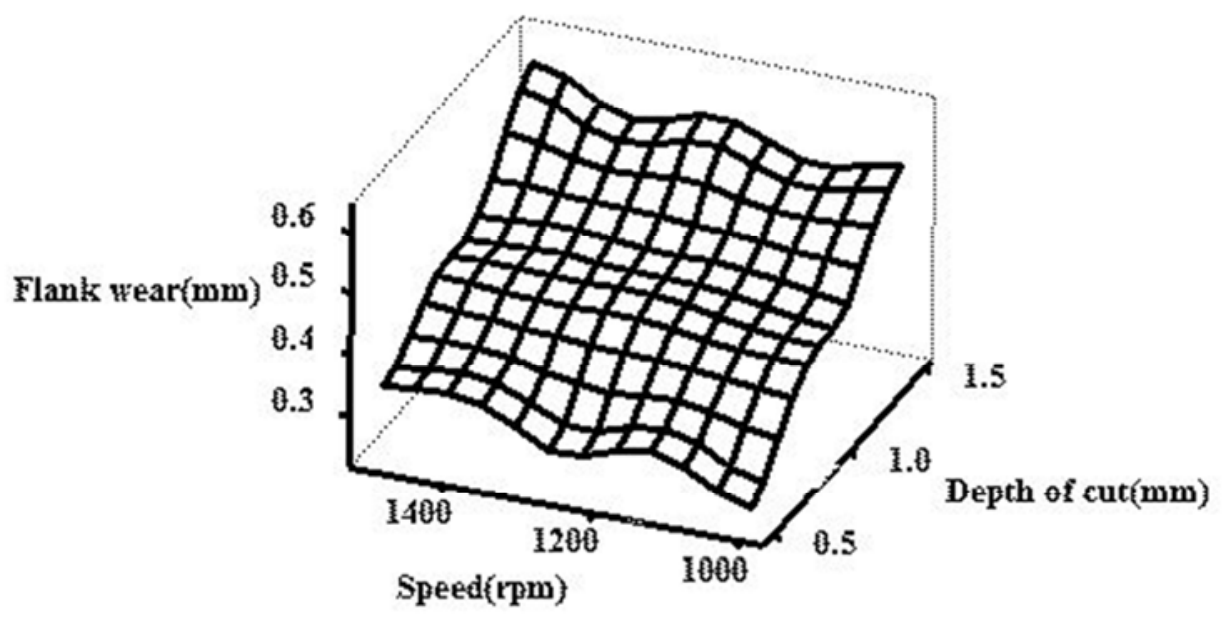

Fig. 9 Interaction between the depth of cut and the cutting speed

\subsubsection{Direct effect on the crater wear}

The crater wear decreases with an increase in the cutting speed and increases with the increase in the depth of cut and the feed rate as shown in Fig.10 (a-c). Furthermore, in the crater wear, the magnitudes of slope vary from 0.2087 to 0.1551 for the depth of cut, from 0.2448 to 0.2584 for the cutting speed, and from 0.1031 to 0.1225 for the feed rate.

The cutting speed and the feed rate show a parabolic trend while the depth of cut follows a linear trend towards the crater wear at middle and higher levels. At the lower level, the crater wear increases with an increase in the feed rate as shown in Fig.10 (a). At the higher and middle levels, the crater wear initially increases with an increase in the feed rate but it decreases at very high feed rate values as shown in Figs.10 (b) and 10 (c).

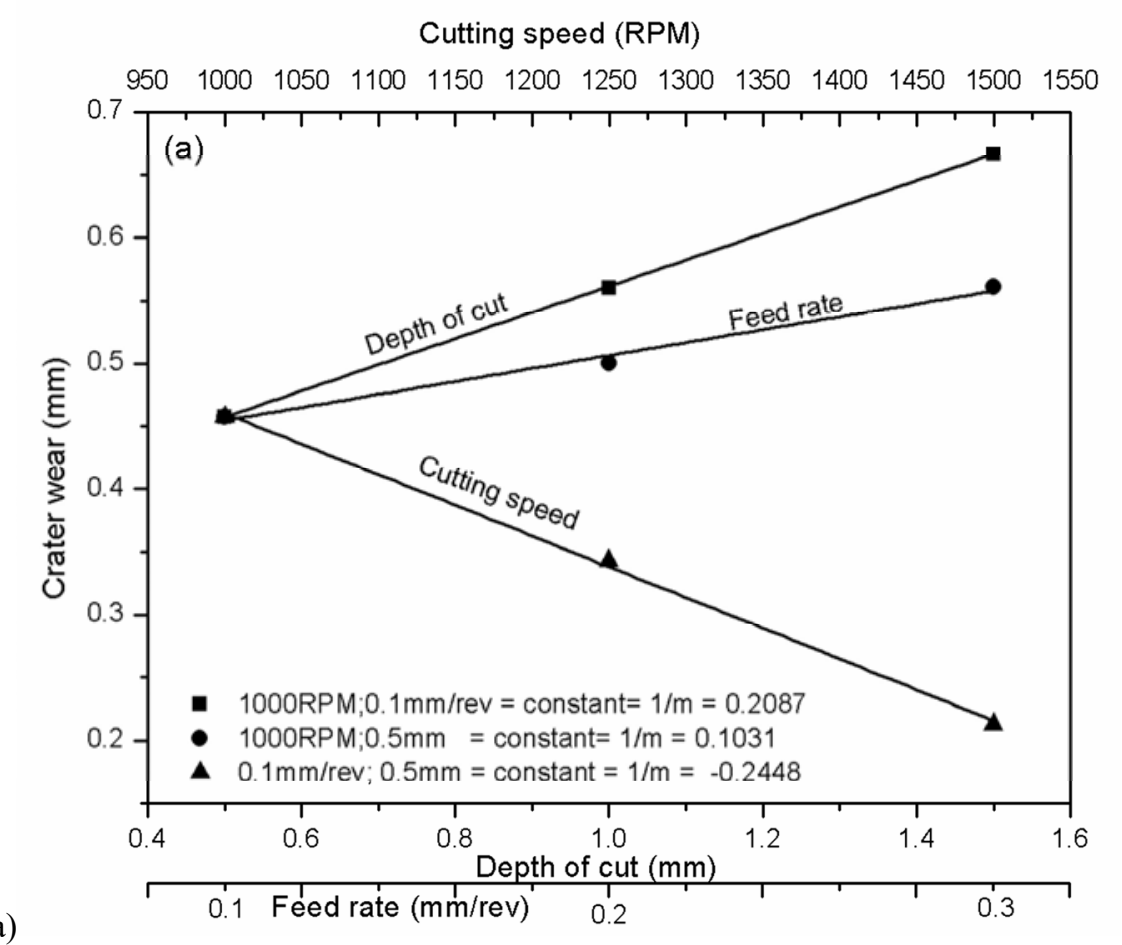




\section{Cutting speed (RPM)}

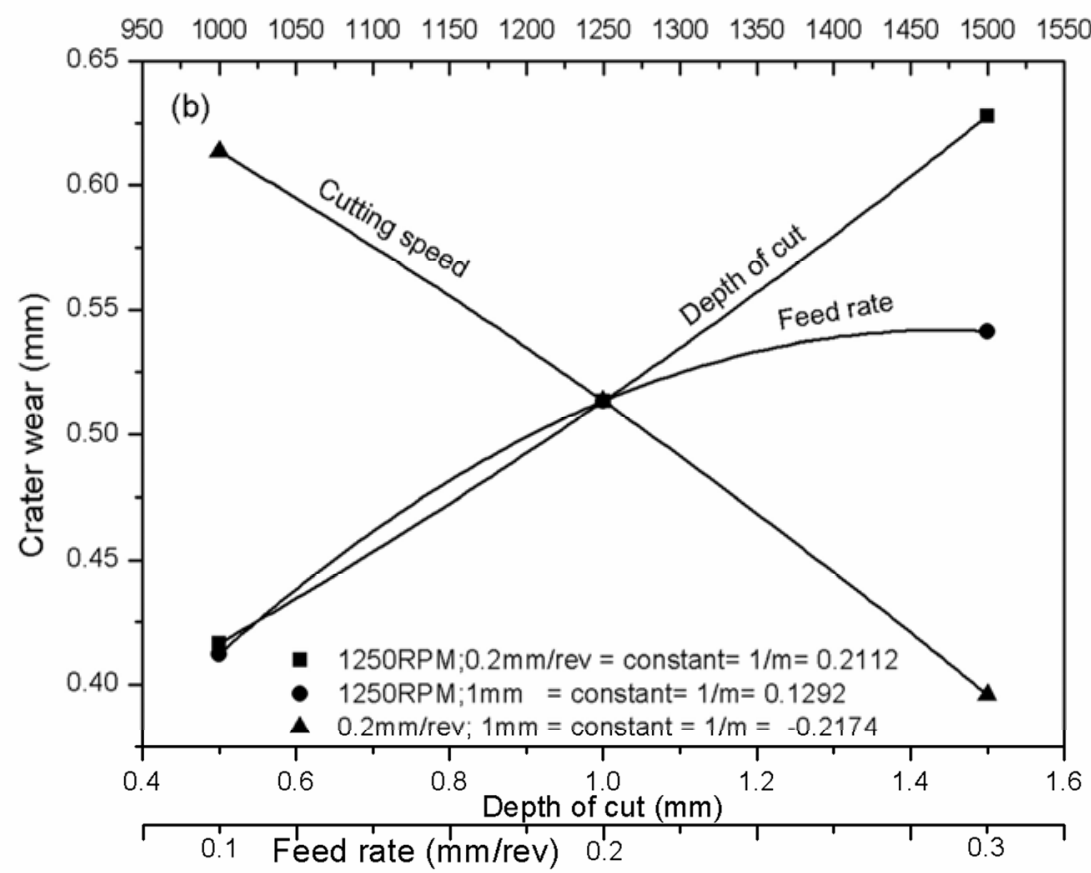

b)

Cutting speed (RPM)

$\begin{array}{lllllllllllll}950 & 1000 & 1050 & 1100 & 1150 & 1200 & 1250 & 1300 & 1350 & 1400 & 1450 & 1500 & 1550\end{array}$

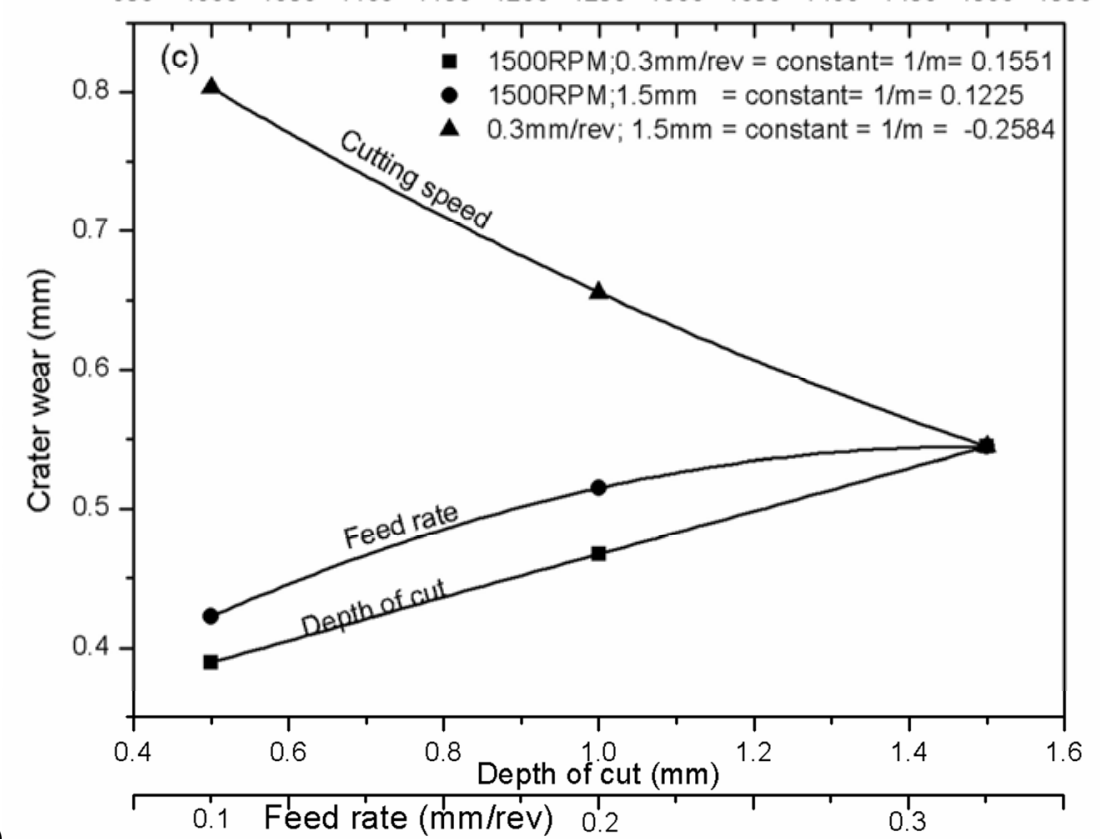

c)

Fig. 10 The direct effects on the crater wear at (a) lower, (b) middle and (c) higher levels

\subsubsection{Interaction effect on the crater wear}

The effect of an increase in the cutting parameters on the crater wear is presented graphically in Figs.11-13.

In Fig.11, the crater wear decreases with an increase in the cutting speed and with a decrease in the feed rate. The contact pressure considerably increases with an increasing feed rate. 


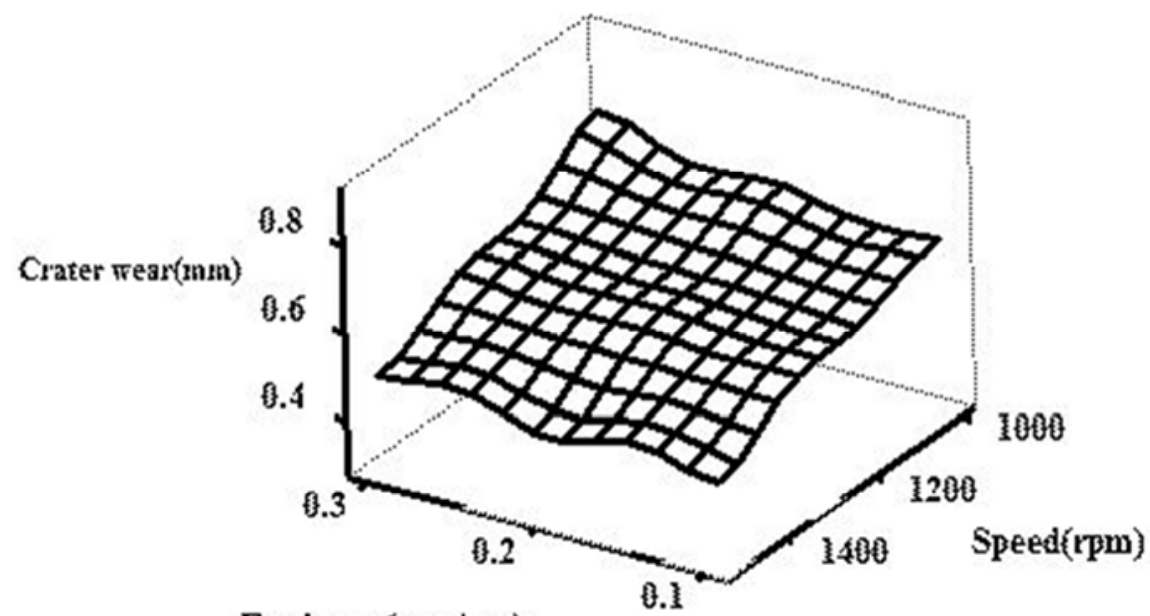

Feed rate(mmirev)

Fig. 11 Interaction between the cutting speed and the feed rate

From Fig.12, one can note that there is an increase in the crater wear as there is an increase in the feed rate and the depth of cut.

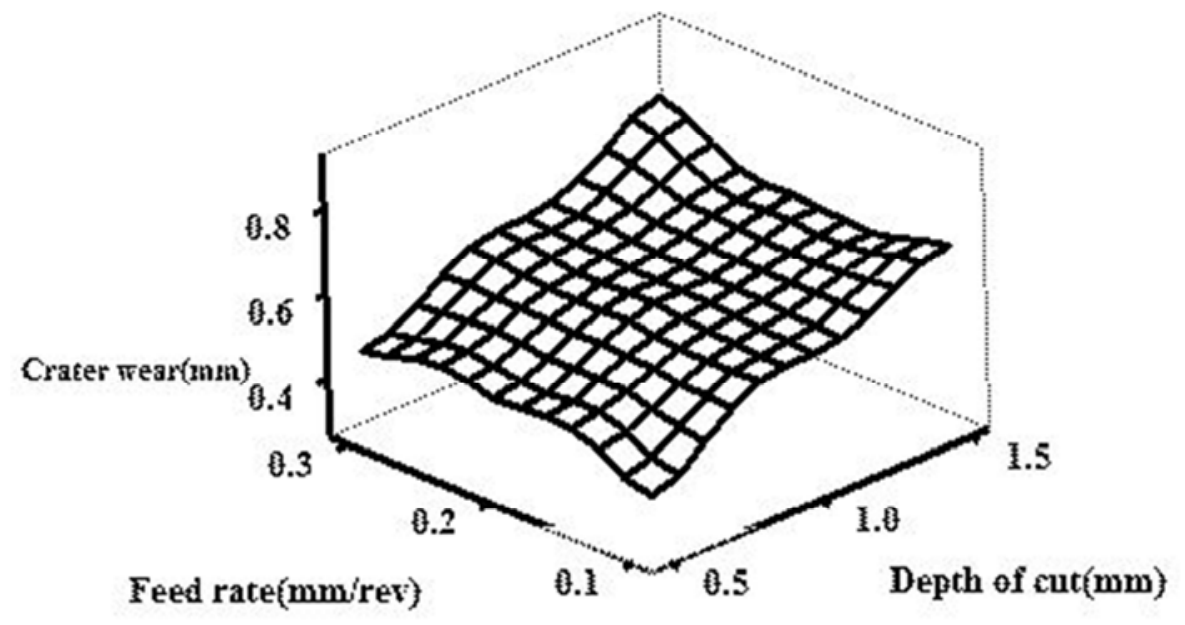

Fig. 12 Interaction between the feed rate and the depth of cut

From Fig.13, it is obvious that when the cutting speed decreases and the depth of cut increases the crater wear increases gradually. It is shown that the crater wear rate is very low for cryogenically treated insert.

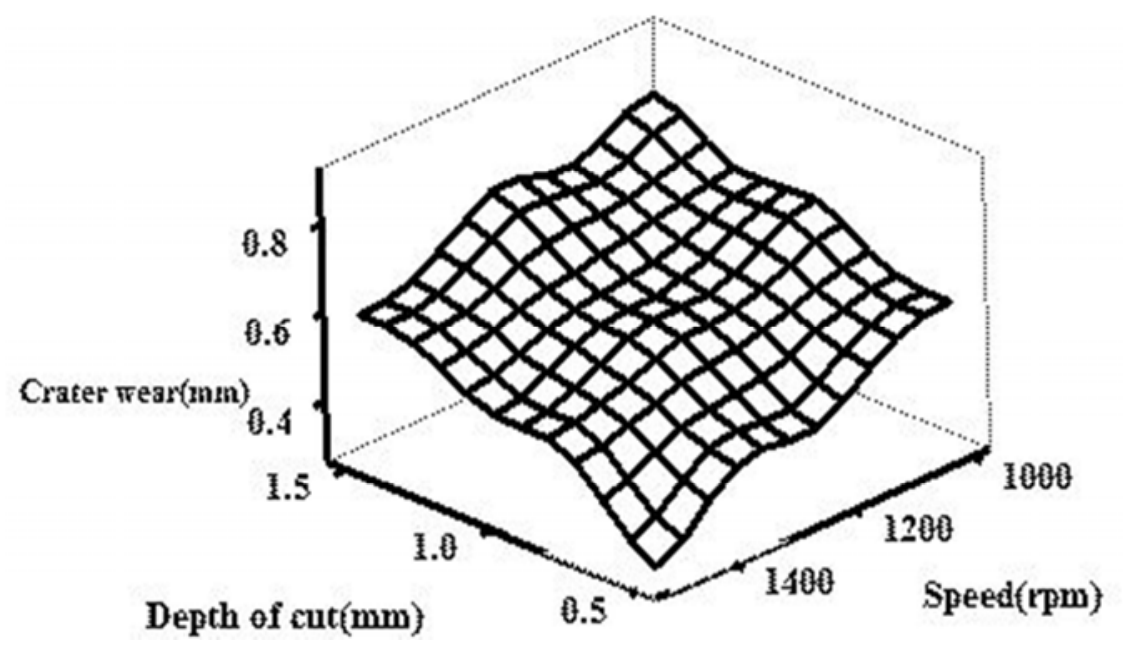

Fig. 13 Interaction between the depth of cut and the cutting speed 


\section{Conclusions}

The wear of cryogenically treated cutting tool was investigated in some laboratory experiments carried out on AISI4340 steel. Based on the experiment results, the following conclusions were drawn:

- The SEM analysis shows that the resistance to wear (both to the flank and crater wear) of cryogenically treated carbide inserts is higher than that of untreated inserts due to the presence of $\eta$-carbides. It is further concluded that the effect of cryogenic treatment is an increase in the size of the carbide particles of the inserts.

- Since the X-ray diffraction analysis confirms the presence of $\eta$-carbides in the CNMG120408SMRH13A cutting tool insert, the intensity values of peaks are significantly increased.

- The adequacy of the model was tested by the $F$-test which indicates that the developed response surface equation is in good agreement with the observed data.

- Results obtained from the mathematical model developed for investigating the tool wear using the Response Surface Methodology (RSM) show an excellent correlation with the experimental data. Consequently, it may be concluded that the model possesses great predictive power in practical applications.

Based on the experiments, it is clear that the response surface methodology approach is a very efficient way of calculating the tool wear during the industrial machining process with the same tooling and setup. RSM allows the identification and quantification of the interactions among the chosen parameters and thus contributes to a more precise determination of the responses.

\section{REFERENCES}

[1] Liu K, Li X, Rahman M, Liu X.: CBN tool wear in ductile cutting of tungsten carbide. Wear.255 (2003) 13 44-51.

[2] V. S. Damdhar, K. N. Pande, D. R. Peshwe and C. L. Gogte: To Investigate the Wear Mechanism on Cryogenic Treatment of PTFE-Mica Filled Composite Coatings in Cookware. Trans Indian Inst Met. (2014). DOI 10.1007/s12666-014-0491-7.

[3] Bhateja A, Bhardwaj J, Singh M, Pal SK.: Optimization of Different Performance Parameters i.e. Surface Roughness, Tool Wear Rate and Material Removal Rate with the Selection of Various Process Parameters Such as Speed Rate, Feed Rate, Specimen Wear, Depth Of Cut in CNC Turning of EN24 Alloy Steel An Empirical Approach. Int J Eng Sci. 2 (2013) 103-113.

[4] Jeon J, Kim S.: Optical flank wear monitoring of cutting tools by image processing. Wear. 127 (1988) 207-17. DOI:10.1016/0043-1648(88)90131-7

[5] Chou YK, Evans CJ.: Tool wear mechanism in continuous cutting of hardened tool steels. Wear.212 (1997) 59-65. DOI:10.1016/S0043-1648(97)00139-7

[6] Panigrahi SK, Jayaganthan R.: Analysis of the Tool Condition Monitoring System Using Fuzzy Logic and Signal Processing. Metall Mater Trans A. 42 (2011) 3208-17. DOI:10.1007/s11661-011-0723-y

[7] Natasha, A. R.; Ghani, J. A.; Che Haron, C. H.; Syarif, J. \& Musfirah, A. H.: Temperature at the tool-chip interface in cryogenic and dry turning of aisi 4340 using carbide tool. Int j simul model 15 (2016) 2, 201212. DOI:10.2507/IJSIMM15(2)1.314

[8] Singh H, Kumar P.: Tool wear optimization in turning operation by Taguchi method. Indian J Eng Mater S. 11 (2004) 19-24. 
[9] Davim JP, Figueira L.: Machinability evaluation in hard turning of cold work tool steel (D2) with ceramic tools using statistical techniques. Mater Design. 28 (2007) 1186-91. DOI:10.1016/j.matdes.2006.01.011

[10] K.S. Prasad, D.S.K. Murali, N. Eswara Prasad and A. K. Mukhopadhyay: Influence of microstructure on the subzero temperature tensile properties of heat treated AA7010 plates. Trans Indian Inst Met, 63 (2010) 799 - 805. DOI:10.1007/s12666-010-0122-X

[11] Gill SS, Singh R, Singh H, Singh J.: Wear behaviour of cryogenically treated tungsten carbide inserts under dry and wet turning conditions. Int J Mach Tool Manu. 49 (2009) 256-60. DOI:10.1016/j.ijmachtools.2008.11.001

[12] M.K. Samal, B.K. Dutta, H.S. Kushwaha, R. Daga and G. Bandyopadhyay: Creep damage evaluation of a power plant header using combined FEM analysis and quantitative metallography. Trans Indian Inst Met, 63 (2010) 411-416. DOI:10.1007/s12666-010-0056-3

[13] K. Surekha and A. Els-Botes: Effect of Cryotreatment on Tool Wear Behaviour of Bohler K390 and AISI H13 Tool Steel During Friction Stir Welding of Copper. Trans Indian Inst Met 65 (2012) 259-264. DOI:10.1007/s12666-012-0127-8

[14] Çiçek A, Kara F, Kivak T, Ekici E.: Evaluation of machinability of hardened and cryo-treated AISI H13 hot work tool steel with ceramic inserts. Int J Refract Met H. 41 (2013) 461-469. DOI:10.1016/j.ijrmhm.2013.06.004

[15] Özbek NA, Çiçek A, Gülesin M, Özbek O.: Investigation of the effects of cryogenic treatment applied at different holding times to cemented carbide inserts on tool wear. Int J Mach Tool Manu. 86 (2014) 34-43. DOI: 10.1016/j.ijmachtools.2014.06.007

[16] Bhuvnesh Bhardwaj, Rajesh Kumar, Pradeep K. Singh: Prediction of Surface Roughness in Turning of EN 353 Using Response Surface Methodology. Trans Indian Inst Met, (2013). DOI: 10.1007/s12666013-0346-7.

[17] Strano M, Albertelli P, Chiappini E, Tirelli S.: Wear behaviour of PVD coated and cryogenically treated tools for Ti-6Al-4V turning. Int J Met Form. 8 (2015) 601-611.

[18] Ekici E, Motorcu AR.: Evaluation of drilling Al/SiC composites with cryogenically treated HSS drills. Int $J$ Adv Manuf Tech. 74 (2014) 1495-505. DOI:10.1007/s00170-014-6085-z

[19] Aggarwal A, Singh H, Kumar P, Singh M.: Optimizing power consumption for CNC turned parts using response surface methodology and Taguchi's technique-A comparative analysis. J Mater Process Tech. 200 (2008) 373-84. DOI:10.1016/j.jmatprotec.2007.09.041

[20] Sharma P, Verma A, Sidhu R, Pandey O.: Process parameter selection for strontium ferrite sintered magnets using Taguchi L9 orthogonal design. J Mater Process Tech. 168 (2005) 147-51. DOI:10.1016/j.jmatprotec.2004.12.003

[21] Montgomery DC. Design and analysis of experiments: Wiley New York; 1984.

[22] Philip JR. Taguchi techniques for quality engineering. McGraw-Hill, New York, USA; 1988.

$\begin{array}{ll}\text { Submitted: } & 15.3 .2016 \\ \text { Accepted: } & 02.01 .2017\end{array}$

